\title{
O desempenho das exportações brasileiras na perspectiva dos seus principais parceiros comerciảis: uma análise pelo método de Vetores Auto-Regressivos (VAR)
}

\author{
The performance of brazilian exports in the perspective of its major business partners: \\ an analysis by the method of Auto-Regressive Vectors (VAR)
}

\section{Gabriela Lima Aidar'; Larissa Naves Deus"}

\begin{abstract}
Resumo
Este trabalho tem como objetivo analisar o desempenho das exportações brasileiras bilaterais, de acordo com os seus cinco principais parceiros comerciais, quais sejam: China, Estados Unidos, Argentina, Holanda e Alemanha. Para tanto, o método utilizado é o de Vetores Auto-Regressivos (VAR), tendo como variáveis dependentes a volatilidade da taxa de câmbio real efetiva, a variação da taxa de câmbio real bilateral, a variação do PIB de cada país parceiro e um preço referência para cada relação, abrangendo o período de Janeiro de 1995 a Junho de 2015. Os principais resultados apontam para comportamentos muito semelhantes entre os países parceiros, principalmente quando se observa as influências do PIB dos diferentes países, assim como da taxa de câmbio real bilateral, impulsionando as exportações brasileiras direcionadas para cada país.
\end{abstract}

Palavras-chave: Exportações; Parceiros Comerciais; Vetores Auto-Regressivos

\begin{abstract}
This work aims to analyze the performance of bilateral Brazilian exports, according to its five main trading partners: China, the United States, Argentina, the Netherlands and Germany. In order to do so, the method used is Auto-Regressive Vectors (VAR), with dependent variables being the effective real exchange rate volatility, the variation of the bilateral real exchange rate, the GDP variation of the partner country and a reference price for each relationship, analyzed from January 1995 to June 2015. The main results point to very similar behavior among countries, especially when one observes the influences of each country's GDP and the bilateral real exchange rate, boosting Brazilian exports for each partner.
\end{abstract}

Key-words: Exports; Trade Partners; Auto-Regressive Vectors

\footnotetext{
TUniversidade Federal de Ubertändia - gabrielaaidarl@gmail.com

II Universidade Federal de Uberlândia - larissand6@hotmail.com
} 


\section{Introdução}

O processo de globalização financeira iniciou-se em meados da década de 1980, no intuito de buscar certo 'equilíbrio' entre os Balanços de Pagamentos das diversas economias mundiais. No Brasil, a abertura financeira e também comercial deu-se apenas no início da década de 1990, com o Governo Collor. As aberturas se justificavam, de acordo com Painceira e Carcanholo (2004), por diversos motivos, desde o aumento da eficiência dos sistemas financeiros domésticos, a possibilidade de minimização dos riscos por parte dos investidores, domésticos e externos e até mesmo por uma maior uniformização das políticas econômicas.

Por outro lado, existem inúmeras críticas em torno desse processo, que perpassam, no caso brasileiro, por exemplo, à maneira abrupta pela qual as reformas foram colocadas em marcha, o que contribuiu sobremaneira para o aumento da vulnerabilidade externa do país. Este tema ganha contornos especiais por se ter no comportamento da taxa de câmbio os reflexos da intensa abertura comercial e financeira iniciadas na década de 1990 e intensificadas no decorrer dos anos. Para além, o Brasil enfrenta um dilema no que toca essa questão, pois, por ser claramente conhecido como o país que tem uma das taxas de juros mais elevadas do mundo, atrai uma quantidade considerável de captais externos, especulativos, portanto, que tendem a valorizar o câmbio. De outro lado, o país é altamente dependente da performance de suas exportações, o que torna evidente a preocupação com a excessiva valorização cambial.

Deste modo, observa-se a intensificação das discussões acerca dos efeitos desses processos na teoria econômica e como eles ou os próprios elementos envolvidos nesses processos, como a taxa de juros, a taxa de câmbio, as relações comerciais, dentre outros, são capazes ou não de afetar o crescimento econômico a longo prazo. Para o caso brasileiro, em especial, os debates concentram-se, principalmente, em torno da taxa de câmbio, por ser um país ainda muito dependente de suas exportações de commodities agrícolas e de minerais, e que geralmente é 'favorecido' pelo comportamento do câmbio se mostrar, na maior parte do tempo, desvalorizado em relação ao dólar. Dessa maneira, justifica-se a importância de se discutir e buscar compreender os determinantes das exportações brasileiras e suas principais relações comerciais.

Portanto, o objetivo deste artigo é buscar, por meio da análise de Vetores Auto Regressivos (VAR), quais as variáveis de maior relevância para explicar o desempenho das exportações brasileiras direcionadas aos seus cinco principais parceiros - China, Estados Unidos, Argentina, Holanda e Alemanha -, escolhidos de acordo com suas respectivas participações nas exportações brasileiras. As variáveis foram buscadas de acordo com a discussão da literatura sobre o processo de globalização financeira, levando-se em conta o comportamento do Brasil como um país emergente. Além disso, considera-se a sua relação com países considerados desenvolvidos, como é o caso dos Estados Unidos, Holanda e Alemanha, países em franca expansão, caso da China, e com países que possuem um posicionamento muito semelhante ao brasileiro em relação ao mercado mundial, como a Argentina. O período de análise tem início em Janeiro de 1995, considerando a abertura financeira e comercial do Brasil, além de uma maior estabilidade do real, até Junho de 2015, data em que todos os dados utilizados na análise estão disponibilizados para todos os países em questão.

Para tanto, o artigo foi divido em três seções além desta introdução e das considerações finais. A primeira seção consiste em apresentar um breve panorama da discussão sobre globalização financeira e dos seus efeitos sobre as economias emergentes. Feito isso, a seção seguinte se propõe a identificar e explicar a importância das variáveis escolhidas e apresentar todos os testes necessários, que garantam a estacionariedade das séries temporais e que determinem as defasagens do método VAR de cada modelo. Assim, na seção 3, as análises dos resultados empíricos serão apresentadas, buscando-se compreender se e como cada variável endógena é capaz de influenciar o desempenho das exportações brasileiras direcionadas a cada um dos países parceiros analisados.

\section{Comércio internacional, o processo de globalização financeira e a discussão recente sobre}

\section{o papel das exportações}

O comércio internacional veio, ao longo dos anos, tendo muito destaque no desenvolvimento econômico dos países. Antes explicado essencialmente pela disponibilidade de fatores, o comércio mundial passa a ser visto como resultado das decisões das empresas e das políticas dos países, ou seja:

(...) o comércio entre nações pode ser afetado tanto por fatores macroeconômicos (taxa de câmbio, renda doméstica e mundial, incidência de tributos, taxa de juros, investimento interno e externo, entre outros), quanto por fatores estruturais (infraestrutura, tecnologia, política comercial, etc) (BITTENCOURT; CAMPOS, 2014, p. 159).

Neste sentido, tanto fatores relacionados à demanda, quanto fatores relacionados à oferta exercem forte influ- 
ência no desempenho exportador de um país, constituindo elementos determinantes das exportações de cada país. Pelo lado da oferta de exportações, são muitos os fatores que podem afetar a capacidade de exportação de determinada empresa, sobretudo se esta se encontra num país desenvolvido ou em desenvolvimento. Como o Brasil é uma economia em desenvolvimento, podemos citar como principais fatores determinantes da exportação pelo lado da oferta o comportamento da taxa de câmbio, a utilização da capacidade instalada do país, o produto potencial que essa economia pode gerar, além da volatilidade cambial que este está sujeito.

Por outro lado, pode-se elencar como principais fatores determinantes da exportação pelo lado da demanda, em economias em desenvolvimento, o índice de preço relativo do produto em questão e o nível de renda mundial, que pode ser aproximado pelo nível do PIB dos países. Basicamente, pode-se considerar que "a demanda por exportações domésticas será uma parte da demanda estrangeira por importações. A demanda estrangeira por importações dependerá do nível de renda estrangeira, porque ela é determinada por uma função demanda de consumo" (FROYEN, 2006, p. 664).

Tendo em vista a potencialidade econômica propiciada pelo comércio internacional entre os países, observou-se o incentivo a essa prática em nível mundial e, mais recentemente, o incentivo a se mobilizarem além de produtos e serviços, também capital financeiro, o que ficou conhecido teoricamente como globalização ou liberalização financeira.

O processo de globalização financeira iniciou-se em meados da década de 80, partindo dos países desenvolvidos e se estendendo aos países emergentes. Plihon (1995) explica que o processo de globalização financeira instaurou um mercado unificado do dinheiro em âmbito mundial. Com isso, as empresas e instituições multinacionais, industriais ou financeiras, puderam captar e aplicar recursos em qualquer lugar do mundo, a qualquer tempo, utilizando-se dos modernos instrumentos financeiros que foram sendo criados. As particularidades do processo de globalização financeira trazem à tona a noção de liberalização financeira, que, pode ser identificada, de maneira geral, a partir da livre mobilidade de capitais entre diversos países, da predominância das relações financeiras em detrimento das relações produtivas na economia, da difusão das inovações financeiras facilitando a captação e aplicação de recursos para variados fins, da desregulamentação do setor financeiro, do surgimento de investidores institucionais. Tais medidas funcionam como uma ponte que ligam o mercado financeiro doméstico de determinado país ao mercado financeiro global, integrado.

Diante desse cenário, diversos trabalhos foram desenvolvidos no intuito de se mensurar e analisar os efeitos desse evento no crescimento econômico de longo prazo das economias e no possível surgimento de crises financeiras. Na literatura referente à liberalização financeira há, fundamentalmente, duas visões sobre este processo. Uma primeira visão - de cunho neoclássico - concebe a liberalização financeira como meio de desenvolvimento financeiro e de crescimento da economia no longo prazo. Inclusive, conforme aponta Paula (2009), os defensores da liberalização financeira notam esse processo como um passo certo para o desenvolvimento econômico, pois através dele são gerados canais diretos e indiretos que agem sobre a economia do país. Os canais diretos de influência correspondem ao aumento da poupança externa, menor custo do capital devido à distribuição do risco e através do próprio desenvolvimento do sistema financeiro. Já os canais indiretos dizem respeito à especialização gerada pela integração internacional, ao estímulo às melhores políticas econômicas e ao fortalecimento dos afluxos de capitais, através da sinalização de tais políticas.

Já a visão crítica a este processo aponta que a liberalização está fortemente associada a crises bancárias, cambiais e financeiras, uma vez que há certa fragilidade nos argumentos que justificam tal processo. Isso pois, há imperfeições nos mercados financeiros, decorrentes tanto de assimetrias de informação entre um agente e outro, quanto da crença na incerteza fundamental que está inerente nas decisões econômicas e não econômicas dos agentes, o que não garante, à priori, que todos os canais elencados acima sejam satisfeitos no processo de liberalização financeira e comercial (DAMASCENO, 2007).

Belluzzo (1997) chama a atenção para a inserção de diversos países nesse processo de globalização de maneira ética e hierarquizada e ainda ressalta que "os Estados Unidos usufruindo de seu poder militar e financeiro [deram-se] ao luxo de impor a dominância de sua moeda, ao mesmo tempo em que [mantinham] um déficit elevado e persistente em conta corrente e uma posição devedora externa" (ibidem, p. 187). À luz desse posicionamento, o autor chama atenção ao período da década de 90 , em que as políticas monetárias ainda sofriam constrangimentos do câmbio,

(...) decorrentes da coexistência entre mercados financeiros 'globalizados' e um sistema internacional plurimonetário, com taxas flutuantes de câmbio entre as 3 principais moedas. Isto não seria tão problemático se o país detentor da moeda central não fosse, ao mesmo tempo, devedor líquido e cronicamente deficitário em conta corrente (BELLUZZO, 1997, p.182).

Kose et al. (2009), por meio da análise de alguns trabalhos, afirmam que a liberalização dos fluxos de capitais de um país não necessariamente leva a uma aceleração do crescimento econômico e que os principais benefícios desse processo são indiretos, à exemplo da estabilidade macroeconômica e desenvolvimento das instituições. À nível da firma, os autores trazem alguns trabalhos que sugerem que firmas de alta tecnologia são mais dependentes do 
capital externo, por isso experimentam um maior crescimento, assim como no caso de indústrias que estão em um período de crescentes oportunidades. Essas firmas registram maiores níveis de crescimento de vendas, investimento e eficiência.

Por sua vez, Rodrik e Subramanian (2009) trazem à tona elementos colocados por autores que carregam outra visão, questionando se de fato, mesmo pela análise à nível da firma, pode-se afirmar que é perceptível a influência da liberalização financeira no crescimento econômico. O questionamento passa desde o argumento de Kose et al. (2009) sobre os melhoramentos que podem ser gerados em relação à macroeconomia e às instituições, afirmando que para se obter resultados benéficos, esses elementos citados já devem existir; até a inclusão de variáveis relacionadas à governança e contratos, como a seleção adversa, a possibilidade de securitização dos ativos, os contratos de derivativos, a baixa transparência e incentivos distorcidos, que podem, de alguma maneira, "blindar" os possíveis efeitos benéficos da liberalização financeira.

Em meio a essa discussão, Bibow (2010) chama a atenção para a necessidade de assumir o homólogo interno para o aumento dos desequilíbrios externos. O autor ainda coloca que ao contrário do que sugeriam as preocupações anteriores sobre os desequilíbrios globais e a possibilidade de quebra do dólar

(...) eram os desequilíbrios internos dos Estados Unidos que se provaram insustentáveis - enquanto o dólar subiu no pico da crise, confirmando seu status de moeda de reserva chave. [...] enquanto as autoridades oficiais em países como a China tem grande quantidade de reservas acumuladas em títulos do governo norte americano, os gastos dos EUA que geraram crescimento da renda não foram realmente impulsionados por dívidas públicas, mas por dívidas privadas (BIBOW, 2010, p.4).

Aizenman e Binici (2015), por sua vez, ressaltam os efeitos da globalização financeira sobre as economias emergentes, com taxas de juros globais e preço dos ativos cada vez mais correlacionados, o que gera um aumento dos spillovers internacionais. A partir disso, os autores afirmam que:

O papel da taxa de câmbio nesses spillovers internacionais depende do regime cambial e das políticas de gestão relacionadas. Por exemplo, de 2010 a 2012, após o período de crise financeira global, os países que pretendem uma recuperação liderada pelas exportações optaram por realizar desvalorizações/depreciações como forma de melhorar a sua competitividade (AIZENMAN; BINICI, 2015, p.2).

Neste particular, Aizenman e Ito (2016) avaliam a abertura de economias do Leste Asiático para os fluxos de capital e acordos cambiais nas últimas décadas, mostrando que tais países buscam por meio da manutenção de altos níveis de reservas, principalmente no caso da China, uma maior estabilidade aos efeitos gerados pelos fluxos de capitais internacionais, não apenas por precaução, mas também para manutenção da estabilidade da taxa de câmbio. A contrapartida disso é a alta liquidez do dólar no mercado mundial que deixa os países emergentes mais vulneráveis a alterações de políticas dos Estados Unidos. No caso dos países da América Latina, os autores mostram que há um nível reduzido de reservas em comparação com a China, mas com abertura financeira e a busca pela estabilidade da taxa de câmbio razoáveis. Então, percebe-se que ambas as economias são muito dependentes da volatididade e do nível de suas taxas de câmbio e, ao mesmo tempo, dependentes do desempenho do dólar no mercado internacional.

Por outro lado, Frankel (2009), na busca por avaliar o regime de câmbio da China após a sua alteração em 2005 por pressões do mercado internacional, advinda principalmente dos Estados Unidos, apontou que o comportamento da cesta de moedas na qual o câmbio chinês está presente tem assinalado um crescimento da importância do euro, mesmo que ainda menor que a representatividade do dólar. Isso indica que, provavelmente, a apreciação do RMB (renminbi - moeda chinesa) em relação ao dólar tem forte ligação com a valorização do euro em relação ao dólar.

Ainda preocupado com o comportamento de países emergentes e do leste asiático, Edwards (2011, p. 1) ressalta que o crescimento desses países é atrelado às suas taxas de câmbio e afirma que "uma taxa de câmbio real, relativamente estável, que não se sobrevaloriza, é um componente-chave das estratégias de desenvolvimento das economias orientadas para o exterior e baseadas em suas exportações”. O autor chama a atenção ainda para o período da última crise financeira global (2007-2009), em que as economias da América Latina tiveram suas moedas valorizadas, principalmente devido à efeitos colaterais externos, por exemplo, com entrada massiva de capitais no pós-crise.

Vieira et al. (2013), complementa um ponto essencial para a análise dessas e de outras economias já citadas, a importância da incorporação da volatilidade da taxa de câmbio real efetiva na análise do crescimento de longo prazo, o que o fazem por meio de uma análise de dados em painel. Os autores mostram com resultados empíricos que uma alta volatilidade, em detrimento do nível da taxa de câmbio real efetiva, pode prejudicar o crescimento de longo prazo. Além disso, Vieira e MacDonald (2016) trazem à tona a influência dessa volatilidade no desempenho das exportações de economias emergentes e exportadoras de petróleo, com destaque para efeitos negativos (ou seja, maiores custos envolvidos nas exportações) no segundo tipo de economia.

Pode-se notar assim, a partir dos trabalhos citados, que há, por um lado, grandes questionamentos acerca dos 
benefícios gerados pelo processo de globalização financeira e, por outro lado, grande destaque ao papel da taxa de câmbio nesse processo, sobretudo para economias emergentes, como a brasileira. À exemplo, Bresser Pereira (2009) destaca em sua análise a importância da taxa de câmbio competitiva, que age no sentido de estimular o crescimento econômico, sobretudo aos países em desenvolvimento. Para além, Araújo (2008) ao analisar Argentina, Brasil, Chile e México, entre 1980 e 2003, conclui que preservar a competitividade e estabilidade cambial significa grande contribuição da política macroeconômica no desempenho econômico desses países. Assim, torna-se clara a importância de se analisar, em pormenores, como o comportamento da taxa de câmbio pode influenciar o desempenho exportador brasileiro, tendo em vista seus principais parceiros comerciais.

\section{Variáveis e Metodologia}

O VAR é uma extensão de um modelo univariado auto-regressivo para séries temporais multivariadas. O modelo é constituído por um sistema de equações lineares dinâmicas, em que cada variável é representada como função de um erro serialmente não correlacionado e, todas as variáveis pertencentes ao sistema possuem o mesmo número de defasagens. As defasagens determinam a ordem do modelo, de modo que VAR (1), por exemplo, representa um modelo vetor auto-regressivo com uma defasagem (Bueno, 2008).

Com a presença do (VAR) existe a possibilidade, segundo Bueno (2011), de se apresentar modelos mais abrangentes, no sentido de serem mais completos, tendo a possibilidade de se restringir as equações do modelo, abrindo a possibilidade de se identificar os parâmetros estruturais do VAR. Isso porque todas as variáveis são apresentadas como endógenas, formando um sistema de equações geradas por MQO, em que todas possuem a mesma quantidade de defasagens. Assim, o VAR se mostra útil para a análise das interações propostas neste trabalho, já que possibilita observar as relações dinâmicas entre as variáveis endógenas consideradas, sem a necessidade de se definir previamente a causalidade entre elas.

\section{As escolha das variáveis e os modelos propostos}

A escolha das variáveis, a realização dos testes e a apresentação dos resultados empíricos são cercadas pela busca de variáveis que possam melhor explicar o desempenho das exportações brasileiras, em relação aos seus cinco principais parceiros comerciais, China, Estados Unidos, Argentina, Holanda e Alemanha. A escolha dos países utilizou o critério dos cinco países que mais importam (em US\$) produtos brasileiros, no acumulado de Outubro de 2015 ao mesmo mês de 2016. A proposta é, assim, expor um modelo distinto para cada relação bilateral, no objetivo de perceber como cada uma das relações bilaterais reagem.

De acordo com o panorama teórico apresentado, justificam-se as escolhas de cada uma das variáveis que resultarão nos modelos propostos. Com o processo de globalização financeira, países que dependem das exportações (X) em grande parte para buscar equilíbrio em suas contas, estão sempre atentos à sua competitividade no mercado internacional. Além de uma moeda competitiva, é desejável que ela seja estável, pois a sua oscilação (junto a outras variáveis) pode afetar diretamente seu desempenho no comércio internacional. Por isso, a volatilidade da taxa de câmbio real efetiva (REERVOL) foi escolhida como proxy para o posicionamento da economia brasileira no mercado mundial. O cálculo da volatilidade foi realizado via modelo ARCH-GARCH $(1,1)$, garantindo a ausência de correlação serial através da análise do correlograma do quadrado dos resíduos (Anexo I); e ausência do efeito ARCH, por meio do teste ARCH LM (Anexo II).

A variação percentual do PIB dos países parceiros (PIB) foi escolhida como proxy para a demanda externa pelos produtos brasileiros. A taxa de câmbio real bilateral (RERBI), por sua vez, é utilizada para representar os preços relativos entre o Brasil e cada um dos cinco países parceiros escolhidos. Por fim, é necessária uma proxy para os preços dos componentes da pauta exportadora brasileira (P). Para a variável $\mathrm{P}$, foram utilizadas a relação de exportação do Brasil por país (em US\$ FOB), por grupo de produtos (Anexos III ao VII), de Janeiro a Outubro de 2016. A partir dessa informação, foi realizada uma ponderação para cada país de acordo com os grupos de maior importância para o mesmo e a cotação dos preços mensais dos produtos de maior representatividade dentro de cada grupo. Com exceção da variável REERVOL, em todas as demais acrescentou-se abreviações para os países em questão: China $(\mathrm{CH})$; Estados Unidos (EUA); Argentina (ARG); Holanda (HOL); Alemanha (AL).

\section{Estacionariedade}

A escolha da utilização do modelo VAR na análise dos cinco modelos propostos para cada um dos casos exige que a estacionariedade de cada variável seja verificada. Para tanto, foram utilizados os testes Dickey-Fuller Aumentado (ADF), Phillips-Perron (PP), Kwiatkowski-Phillips-Schmidt-Shin (KPSS) e o Dickey-Fuller (DF-GLS). Nos 
Quadros 1 a 5, foram apresentados os resultados para os testes. Para todos os testes propostos foram confirmadas as estacionariedades das séries temporais de todas as variáveis escolhidas para cada relação bilateral.

Quadro 1 - Teste de Estacionariedade Brasil/China

\begin{tabular}{|c|c|c|c|c|}
\hline China & ADF & PP & KPSS & DF-GLS \\
\hline $\begin{array}{l}\text { REERVOL } \\
\text { t-estatísitico } \\
\text { (Probabilidade) }\end{array}$ & $\begin{array}{c}-3.022126^{* *} \\
(0.0343)\end{array}$ & $\begin{array}{c}-2.784790^{*} \\
(0.0619)\end{array}$ & $\begin{array}{c}0.448920^{* *} \\
-\end{array}$ & $\begin{array}{c}-2.717917^{* * *} \\
-\end{array}$ \\
\hline $\begin{array}{l}\text { DXCH } \\
\text { t-estatísitico } \\
\text { (Probabilidade) }\end{array}$ & $\begin{array}{c}-3.137444^{* *} \\
(0.0252)\end{array}$ & $\begin{array}{c}1.876940^{* *} \\
(0.0000)\end{array}$ & $\begin{array}{c}0.165529^{* * *} \\
-\end{array}$ & $\begin{array}{c}2.883533^{* * *} \\
-\end{array}$ \\
\hline $\begin{array}{l}\text { DRERBICH } \\
\text { t-estatísitico } \\
\text { (Probabilidade) }\end{array}$ & $\begin{array}{c}-11.802830^{* * *} \\
(0.0000)\end{array}$ & $\begin{array}{c}-11.507510^{* * *} \\
(0.0000)\end{array}$ & $\begin{array}{c}0.113671^{* * *} \\
-\end{array}$ & $\begin{array}{c}-11.614010^{* * *} \\
-\end{array}$ \\
\hline $\begin{array}{l}\text { PCH } \\
\text { t-estatísitico } \\
\text { (Probabilidade) }\end{array}$ & $\begin{array}{c}-11.713150^{* * *} \\
(0.0000)\end{array}$ & $\begin{array}{c}-11.713150^{* * *} \\
(0.0000)\end{array}$ & $\begin{array}{c}0.074526^{* * *} \\
-\end{array}$ & $\begin{array}{c}-11.575250^{* * *} \\
-\end{array}$ \\
\hline $\begin{array}{l}\text { PIBCH } \\
\text { t-estatísitico } \\
\text { (Probabilidade) }\end{array}$ & $\begin{array}{c}-9.773580^{* * *} \\
(0.0000)\end{array}$ & $\begin{array}{c}-84.983720^{* * *} \\
(0.0000)\end{array}$ & $\begin{array}{c}0.263151^{* * *} \\
-\end{array}$ & $\begin{array}{c}0.329575 \\
-\end{array}$ \\
\hline
\end{tabular}

Fonte: Elaboraçãoprópria/Eviews 9.0

*** estacionária em $1 \%$

** estacionária em 5\%

* estacionária em $10 \%$

Quadro 2 - Teste de Estacionariedade Brasil/Estados Unidos

\begin{tabular}{|c|c|c|c|c|}
\hline Estados Unidos & ADF & PP & KPSS & DF-GLS \\
\hline $\begin{array}{l}\text { DXEUA } \\
\text { t-estatísitico } \\
\text { (Probabilidade) }\end{array}$ & $\begin{array}{c}-22.41054^{* * *} \\
(0.0000)\end{array}$ & $\begin{array}{c}-25.64382^{* * *} \\
(0.0000)\end{array}$ & $\begin{array}{c}0.037173^{* * *} \\
-\end{array}$ & $\begin{array}{c}-22.43716^{* * *} \\
-\end{array}$ \\
\hline $\begin{array}{l}\text { DRERBIEUA } \\
\text { t-estatísitico } \\
\text { (Probabilidade) }\end{array}$ & $\begin{array}{c}-11.54848^{* * *} \\
(0.0000)\end{array}$ & $\begin{array}{c}-11.93511^{* * *} \\
(0.0000)\end{array}$ & $\begin{array}{c}0.169587^{* * *} \\
-\end{array}$ & $\begin{array}{c}-11.33878^{* * *} \\
-\end{array}$ \\
\hline $\begin{array}{l}\text { PEUA } \\
\text { t-estatísitico } \\
\text { (Probabilidade) }\end{array}$ & $\begin{array}{c}-11.55132^{* * *} \\
(0.0000)\end{array}$ & $\begin{array}{c}-12.09756^{* * *} \\
(0.0000)\end{array}$ & $\begin{array}{c}0.149929^{* * *} \\
-\end{array}$ & $\begin{array}{c}-11.49906^{* * *} \\
-\end{array}$ \\
\hline $\begin{array}{l}\text { PIBEUA } \\
\text { t-estatísitico } \\
\text { (Probabilidade) }\end{array}$ & $\begin{array}{c}-3.728951^{* * *} \\
(0.0000)\end{array}$ & $\begin{array}{c}-18.48820^{* * *} \\
(0.0000)\end{array}$ & $0.623701^{* * *}$ & $-2.624231^{* * *}$ \\
\hline
\end{tabular}

Fonte: Elaboraçãoprópria/Eviews 9.0

*** estacionária em $1 \%$

** estacionária em $5 \%$

* estacionária em $10 \%$ 
Quadro 3 - Teste de Estacionariedade Brasil/Argentina

\begin{tabular}{lcccc}
\hline \multicolumn{1}{c}{ Argentina } & ADF & PP & KPSS & DF-GLS \\
\hline DXARG & $-4.102897^{* * *}$ & $-20.88357^{* * *}$ & $0.066780^{* * *}$ & -4.063556 \\
t-estatísitico & $(0.0001)$ & $(0.0000)$ & - & - \\
(Probabilidade) & & & & \\
DRERBIARG & $-9.563686^{* * *}$ & $-9.049056^{* * *}$ & $0.061725^{* * *}$ & $-9.357216^{* * *}$ \\
t-estatísitico & $(0.0000)$ & $(0.0000)$ & - & - \\
(Probabilidade) & & & $-14872^{* * *}$ & $-11.72909^{* * *}$ \\
PARG & $-11.75348^{* * *}$ & $-12.28955^{* * *}$ & $0.1480)$ & - \\
t-estatísitico & $(0.0000)$ & $(0.0000)$ & - & $-2.132528^{* * *}$ \\
(Probabilidade) & & & - & - \\
PIBARG & -2.481921 & $-18.82152^{* * *}$ & $0.110295^{* * *}$ & - \\
t-estatísitico & $(0.1212)$ & $(0.0000)$ & & - \\
(Probabilidade) & & & & \\
\hline
\end{tabular}

Fonte: Elaboraçãoprópria/Eviews 9.0

*** estacionária em $1 \%$

** estacionária em $5 \%$

* estacionária em $10 \%$

Quadro 4- Teste de Estacionariedade Brasil/Holanda

\begin{tabular}{lcccc}
\hline \multicolumn{1}{c}{ Holanda } & ADF & PP & KPSS & DF-GLS \\
\hline DXHOL & $-5.161448^{* * *}$ & $-34.35615^{* * *}$ & $0.133648^{* * *}$ & -1.014726 \\
t-estatísitico & $(0.0000)$ & $(0.0000)$ & - & - \\
(Probabilidade) & & & & \\
DRERBIHOL & $-13.39574^{* * *}$ & $-13.26469^{* * *}$ & $0.053143^{* * *}$ & $-12.87874^{* * *}$ \\
t-estatísitico & $(0.0000)$ & $(0.0000)$ & - & - \\
(Probabilidade) & & & $-183026^{* * *}$ & $-9.905286^{* * *}$ \\
PHOL & $-9.888930^{* * *}$ & $-10.25752^{* * *}$ & 0.180. & - \\
t-estatísitico & $(0.0000)$ & $(0.0000)$ & - & $-4.501681^{* * *}$ \\
(Probabilidade) & & & - & - \\
PIBHOL & $-5.161448^{* * *}$ & $-17.71739^{* * *}$ & $0.679691^{*}$ & - \\
$t$-estatísitico & $(0.0000)$ & $(0.0000)$ & & - \\
(Probabilidade) & & & & \\
\hline
\end{tabular}

Fonte: Elaboraçãoprópria/Eviews 9.0

*** estacionária em $1 \%$

** estacionária em $5 \%$

* estacionária em $10 \%$ 
Quadro 5 - Teste de Estacionariedade Brasil/Alemanha

\begin{tabular}{lcccc}
\hline \multicolumn{1}{c}{ Alemanha } & ADF & PP & KPSS & DF-GLS \\
\hline DXAL & $-24.64401^{* * *}$ & $-34.35615^{* * *}$ & $0.133648^{* * *}$ & -1.014726 \\
t-estatísitico & $(0.0000)$ & $(0.000)$ & - & - \\
(Probabilidade) & & & & \\
DRERBIAL & $-13.39574^{* * *}$ & $-13.26469^{* * *}$ & $0.053143^{* * *}$ & $-12.87874^{* * *}$ \\
t-estatísitico & $(0.0000)$ & $(0.0000)$ & - & - \\
(Probabilidade) & & & & \\
PAL & $-9.888930^{* * *}$ & $-10.25752^{* * *}$ & $0.183026^{* * *}$ & $-9.905286^{* * *}$ \\
t-estatísitico & $(0.0000)$ & $(0.0000)$ & - & - \\
(Probabilidade) & & & & \\
PIBAL & $-6.109417^{* * *}$ & $-16.57999^{* * *}$ & $0.049213^{* * *}$ & $-5.7525593^{* * *}$ \\
t-estatísitico & $(0.0000)$ & $(0.0000)$ & - & - \\
(Probabilidade) & & & & \\
\hline
\end{tabular}

Fonte: Elaboraçãoprópria/Eviews 9.0

*** estacionária em $1 \%$

** estacionária em 5\%

* estacionária em 10\%

A variável que estará presente em todos os modelos é a volatilidade da taxa de câmbio real efetiva (REERVOL). As seguintes variáveis compõem os modelos que apontam a relação bilateral do Brasil, por ordem de representatividade, na pauta exportadora brasileira:

1- China: DXCH, REERVOL, DRERBICH, PCH, PIBCH;

2 -Estados Unidos: DXEUA, REERVOL, DRERBIEUA, PEUA, PIBEUA;

3 -Argentina: DXARG, REERVOL, DRERBIARG, PARG, PIBARG;

4 -Holanda: DXHOL, REERVOL, DRERBIHOL, PHOL, PIBHOL;

5 -Alemanha: DXAL, REERVOL, DRERBIAL, PAL, PIBAL.

Nas variáveis endógenas apresentadas acima, deve-se levar em consideração a presença do "D" quando se faz necessário realizar a primeira diferença da série, devido a problemas de estacionariedade na série original. Assim, explicitados os 5 modelos propostos, busca-se analisar qual deles possui melhor "poder" de explicação sobre o desempenho das exportações brasileiras destinadas a cada um dos parceiros comerciais.

\section{Seleção do Modelo VAR - LAG Criteria}

A escolha das defasagens de cada modelo, para cada país, se deu por meio do teste de LAG criteria, que abrange o teste sequencial LR modificado (LR) com 5\% de significância, o Final Prediction Error (FPE), o critério Akaike (AIC), o critério Schwarz (SC) e o critério Hannan-Quinn (HQ). No Quadro 6, nos modelos referentes à relação bilateral do Brasil com a China, Estados Unidos, Argentina, Alemanha e Holanda, os critérios sugerem que as defasagens sejam de 3 para cada um dos países. No caso dos Estados Unidos, o critério sugeriu as defasagens de 3 e 6, porém, devido à presença de correlação serial no modelo com 3 defasagens e a grande quantidade de observações, foi rodado um VAR(6) para a análise. A escolha por essas defasagens foram acompanhadas pelo teste LM para garantir a ausência de correlação serial (Anexo VIII) e garantir a eficiência dos modelos propostos. 
Quadro 6 - LAG criteria

\begin{tabular}{|c|c|c|c|c|c|c|}
\hline Defasagens & LogLR & LR & FPE & AIC & SC & HQ \\
\hline \multicolumn{7}{|l|}{ China } \\
\hline 0 & -9662.411 & NA & $9.37 e+28$ & 80.89884 & 80.97156 & 80.92814 \\
\hline 1 & -9220.041 & 862.5292 & $2.85 e+27$ & 77.40620 & 77.84257* & 77.58205 \\
\hline 2 & -9156.121 & 121.9562 & $2.06 e+27$ & 77.08051 & 77.88053 & 77.40289 \\
\hline 3 & -9109.982 & 86.09940 & $1.73 e+27^{*}$ & $76.90362^{*}$ & 78.06729 & $77.37254^{*}$ \\
\hline 4 & -9087.740 & 40.57597 & $1.77 e+27$ & 76.92669 & 78.45401 & 77.54216 \\
\hline 5 & -9069.684 & 32.18283 & $1.88 e+27$ & 76.98481 & 78.87577 & 77.74681 \\
\hline 6 & -9040.547 & $50.71575^{*}$ & $1.82 \mathrm{e}+27$ & 76.95018 & 79.20479 & 77.85873 \\
\hline \multicolumn{7}{|c|}{ Estados Unidos } \\
\hline 0 & -8730.106 & NA & $7.10 \mathrm{e}+25$ & 73.71397 & 73.78714 & 73.74346 \\
\hline 1 & -8257.866 & 920.5685 & $1.63 e+24$ & 69.93980 & 70.37879 & 70.11674 \\
\hline 2 & -8191.694 & 126.2009 & $1.15 e+24$ & 69.59236 & 70.39718 & 69.91675 \\
\hline 3 & -8109.850 & 152.6387 & $7.13 e+23$ & 69.11266 & $70.28331^{*}$ & $69.58450^{*}$ \\
\hline 4 & -8087.846 & 40.10785 & $7.33 e+23$ & 69.13794 & 70.67442 & 69.75724 \\
\hline 5 & -8069.958 & 31.85193 & $7.80 \mathrm{e}+23$ & 69.19796 & 71.10027 & 69.96471 \\
\hline 6 & -8028.372 & 72.29209 & $6.80 \mathrm{e}+23^{*}$ & $69.05799^{*}$ & 71.32613 & 69.97220 \\
\hline \multicolumn{7}{|l|}{ Argentina } \\
\hline 0 & -9184.465 & NA & $3.28 e+27$ & 77.54823 & 77.62139 & 77.57772 \\
\hline 1 & -8742.114 & 862.3033 & $9.70 e+25$ & 74.02628 & 74.46528 & 74.20322 \\
\hline 2 & -8700.363 & 79.62620 & $8.43 e+25$ & 73.88492 & 74.68975 & 74.20932 \\
\hline 3 & -8604.237 & 179.2744 & $4.63 e+25^{*}$ & $73.28470^{*}$ & $74.45535^{*}$ & $73.75655^{*}$ \\
\hline 4 & -8586.620 & 32.11107 & $4.93 e+25$ & 73.34701 & 74.88349 & 73.96631 \\
\hline 5 & -8560.151 & 47.13076 & $4.88 e+25$ & 73.33461 & 75.23692 & 74.10136 \\
\hline 6 & -8537.593 & 39.21532 & $5.00 \mathrm{e}+25$ & 73.35521 & 75.62335 & 74.26942 \\
\hline \multicolumn{7}{|l|}{ Holanda } \\
\hline 0 & -8758.226 & NA & $9.00 e+25$ & 73.95128 & 74.02444 & 73.98077 \\
\hline 1 & -8327.285 & 840.0634 & $2.93 e+24$ & 70.52561 & $70.96460^{*}$ & 70.70255 \\
\hline 2 & -8271.754 & 105.9067 & $2.26 \mathrm{e}+24$ & 70.26797 & 71.07279 & 70.59236 \\
\hline 3 & -8211.689 & 112.0194 & $1.68 \mathrm{e}+24^{*}$ & 69.97206* & 71.14271 & $70.44391^{*}$ \\
\hline 4 & -8195.244 & 29.97572 & $1.81 \mathrm{e}+24$ & 70.04425 & 71.58074 & 70.66355 \\
\hline 5 & -8174.204 & 37.46459 & $1.88 e+24$ & 70.07767 & 71.97998 & 70.84442 \\
\hline 6 & -8152.724 & 37.34059 & $1.94 \mathrm{e}+24$ & 70.10737 & 72.37551 & 71.02158 \\
\hline \multicolumn{7}{|l|}{ Alemanha } \\
\hline 0 & -8483.208 & NA & $8.84 e+24$ & 71.63045 & 71.70361 & 71.65994 \\
\hline 1 & -8037.767 & 868.3272 & $2.54 \mathrm{e}+23$ & 68.08243 & $68.52142^{*}$ & 68.25937 \\
\hline 2 & -7988.400 & 94.15147 & $2.07 e+23$ & 67.87680 & 68.68162 & 68.20119 \\
\hline 3 & -7944.241 & 82.35656 & $1.76 \mathrm{e}+23^{*}$ & $67.71511^{*}$ & 68.88577 & $68.18696^{*}$ \\
\hline 4 & -7927.016 & 31.39706 & $1.89 e+23$ & 67.78073 & 69.31721 & 68.40003 \\
\hline 5 & -7909.256 & 31.62305 & $2.01 e+23$ & 67.84183 & 69.74414 & 68.60858 \\
\hline 6 & -7889.275 & 34.73599 & $2.10 e+23$ & 67.88417 & 70.15232 & 68.79838 \\
\hline
\end{tabular}

Fonte: Elaboração Própria/Eviews 9.0

* Indica a ordem do lag a ser seguida. LR: sequential modified LR test statistic (each test at 5\% level). FPE: Final prediction error. AIC: Akaike information criterion. SC: Schwarz information criterion. HQ: Hannan-Quinn information criterion 


\section{Análise dos Resultados Empíricos - Variáveis Instrumentais}

Os resultados do modelo VAR podem ser analisados através da estimação da Função de Resposta aos Impulsos, em que se verifica o sentido dos efeitos de cada variável (impulso) sobre as demais (resposta). Além disso, há a análise através da decomposição da variância, em que se procura a porcentagem da variância de erro de previsão decorrente de cada variável endógena.

\section{Decomposição da Variância}

$\mathrm{Na}$ análise por decomposição da variância, busca-se entender de que forma as variáveis se relacionam entre si e, neste caso em especial, como a volatilidade da taxa de câmbio real efetiva (REERVOL) - comum a todos os modelos - a taxa de câmbio real bilateral (RERBI), a variação dos preços (P), e a variação do PIB (PIB) - de cada um dos países parceiros - explicam a variável de interesse representada pelas exportações brasileiras direcionadas a cada um dos países (X). Isso, a fim de destacar a importância de cada uma das variáveis e, por consequência, olhar para cada um dos modelos e avaliar se, diante das variáveis escolhidas, quais variáveis possuem mais influência sobre as exportações, se são essas variáveis as mesmas entre os países, ou se cada um tem sua peculiaridade como parceiro comercial do Brasil.

Quadro 7 - Análise da Decomposição da Variância

\begin{tabular}{|c|c|c|c|c|c|c|}
\hline \multicolumn{7}{|c|}{ Decomposição da Variância de DXCH: } \\
\hline Período & S.E. & $\mathrm{DXCH}$ & REERVOL & DRERBICH & $\mathrm{PCH}$ & PIBCH1 \\
\hline 1 & $4.22 \mathrm{E}+08$ & 100.0000 & 0.000000 & 0.000000 & 0.000000 & 0.000000 \\
\hline 5 & $4.59 E+08$ & 85.98265 & 0.836739 & 0.945121 & 3.027881 & 9.207607 \\
\hline 10 & $4.62 \mathrm{E}+08$ & 84.94992 & 0.857129 & 1.086137 & 3.150228 & 9.956584 \\
\hline \multicolumn{7}{|c|}{ Decomposição da Variância de DXEUA: } \\
\hline Período & S.E. & DXEUA & REERVOL & DRERBIEUA & PIBEUA & PEUA \\
\hline 1 & $2.08 \mathrm{E}+08$ & 100.0000 & 0.000000 & 0.000000 & 0.000000 & 0.000000 \\
\hline 5 & $2.45 \mathrm{E}+08$ & 85.69406 & 0.959806 & 2.400507 & 2.691682 & 8.253943 \\
\hline 10 & $2.49 \mathrm{E}+08$ & 83.58039 & 1.212791 & 2.781716 & 3.573570 & 8.851537 \\
\hline \multicolumn{7}{|c|}{ Decomposição da Variância de DXARG: } \\
\hline Período & S.E. & DXARG & REERVOL & DRERBIARG & PIBARG & PARG \\
\hline 1 & $1.38 \mathrm{E}+08$ & 100.0000 & 0.000000 & 0.000000 & 0.000000 & 0.000000 \\
\hline 5 & $1.52 \mathrm{E}+08$ & 95.34254 & 0.174704 & 0.356464 & 1.108058 & 3.018230 \\
\hline 10 & $1.53 \mathrm{E}+08$ & 94.95650 & 0.182111 & 0.375623 & 1.271266 & 3.214500 \\
\hline \multicolumn{7}{|c|}{ Decomposição da Variância de DXHOL: } \\
\hline Período & S.E. & DXHOL & REERVOL & DRERBIHOL & PIBHOL & PHOL \\
\hline 1 & $2.16 \mathrm{E}+08$ & 100.0000 & 0.000000 & 0.000000 & 0.000000 & 0.000000 \\
\hline 5 & $2.50 \mathrm{E}+08$ & 98.96482 & 0.017612 & 0.193430 & 0.510414 & 0.313728 \\
\hline 10 & $2.51 \mathrm{E}+08$ & 98.68138 & 0.025725 & 0.195879 & 0.782723 & 0.314288 \\
\hline \multicolumn{7}{|c|}{ Decomposição da Variância de DXAL: } \\
\hline Período & S.E. & DXAL & REERVOL & DRERBIAL & PIBAL & PAL \\
\hline 1 & 76153841 & 100.0000 & 0.000000 & 0.000000 & 0.000000 & 0.000000 \\
\hline 5 & 88738315 & 91.98525 & 1.182271 & 0.684615 & 1.469081 & 4.678784 \\
\hline 10 & 88939604 & 91.64716 & 1.187562 & 0.717219 & 1.759178 & 4.688882 \\
\hline
\end{tabular}

Fonte: Elaboração Própria/ Saída do Eviews 9.0 
De acordo com o que foi apresentado no Quadro 7, o modelo que representa a relação comercial entre Brasil e China tem como principal determinante das exportações direcionadas a este país a própria exportação. Isso pode ser justificado pela existência de contratos entre os países, além da "facilidade" de negociação e transação de uma relação prévia. Esse comportamento da variável exportação é identificado para todos os modelos dos demais países.

Para além, a variável PIBCH é a segunda maior influenciadora do desempenho das exportações. Isso já era esperado, já que a economia chinesa apresentou e apresenta um período de franca expansão de sua economia, acompanhada da importação de bens primários, principalmente commodities minerais (em especial, minério de ferro) e agrícolas (em especial, soja triturada), considerados representativos para a Balança Comercial brasileira. Junto à isso, houve um favorecimento da valorização do preço dessas commodities, do início de 2005 ao início de 2015 (com uma quebra desse comportamento no período da crise Subprime), o que justifica a variável PCH representar a terceira variável explicativa do modelo. Em seguida, as variáveis RERBICH e REERVOL, nessa ordem, exprimem em menor medida as exportações. Para a volatilidade da taxa de câmbio real efetiva, a menor representação pode ser justificada pela sua composição, que abrange uma gama de países que não se encontram na amostra. Enquanto que para a taxa de câmbio real bilateral, a sua menor parcela de poder explicativo pode ser justificado, em grande medida, pelo alto controle exercido pela China sobre sua taxa de câmbio.

No segundo modelo, que aponta para a parceria comercial com os Estados Unidos, além da própria variável exportação, a que vem em sequência é a variação dos preços, antes mesmo do PIB. Esse resultado pode ser relacionado à capacidade da economia norte americana em alterar os países dos quais importa, devido a seu posicionamento hegemônico na economia mundial e, até mesmo, pela característica dos produtos importados serem de maior valor agregado. Observa-se, também, que a variável RERBIEUA tem maior importância em comparação com o modelo da China, podendo ser explicado pela dependência da economia brasileira ao dólar norte-americano, além do seu papel de moeda referência.

Para o caso da Argentina, o comportamento é semelhante ao que acontece nos Estados Unidos. A pauta exportadora direcionada ao país do terceiro modelo em questão, também tem um valor agregado maior, composta principalmente por automóveis de passageiros e veículos de carga. Em sequência, as exportações são explicadas pelo PIBARG e pelo RERARG. A pouca influência desta última variável pode ser justificada pelo período de congelamento artificial da taxa de câmbio argentina em relação ao dólar, dificultando uma análise do real impacto dessa variável no comércio com o Brasil.

O quarto modelo mostra a relação comercial entre Brasil e Holanda. Apesar da sua pouca representatividade como parceiro comercial, o país foi escolhido por ser o $4^{\circ}$ no ranking dos países que importam do Brasil. A pauta exportadora para o mesmo é bastante homogênea entre commodities agrícolas e minerais e produtos de maior valor agregado. Assim, as exportações são explicadas, além de seu próprio desempenho, pelo PIBHOL, a PHOL e a RERBIHOL.

Por fim, a relação com a Alemanha tem boa parte das suas exportações afetadas pela variação dos preços, já que parcela considerável dos produtos são de maior valor agregado, abrangendo desde medicamentos, até parte de peças de veículos e automóveis de passageiros. Este modelo destoa dos demais, apresentando um resultado distinto ao ter a taxa de câmbio real bilateral com a de menor influência sobre a relação comercial.

\section{Funções Impulso Resposta}

Assim como na análise por decomposição de variância, a Função Impulso Resposta (FIR) é capaz de demonstrar graficamente a resposta das exportações direcionadas a cada país (DXCH, DXEUA, DXARG, DXAL e DXHOL) para as alterações de cada uma das variáveis endógenas escolhidas. Por isso, as Figuras que seguem apresentadas dos 5 modelos propostos se restringiram a mostrar apenas as respostas à essas variações. Para todos os modelos, um impulso gerado pela REERVOL gera, inicialmente uma resposta positiva às exportações, porém, percebe-se ser uma relação instável, mas na maioria do intervalo negativa, justamente pela incerteza envolvida de uma taxa de câmbio muito volátil. A variação positiva inicial pode indicar um processo de ajuste temporário por algum choque externo pelas demais economias, que pode levar a maior procura pelos produtos brasileiros, devido à incerteza futura do nível da REER. À longo prazo, o aumento da demanda gerada pela desvalorização do real, pode levar a um aumento dos preços, reajustando essa resposta e podendo afetar negativamente o efeito, antes positivo. Já no caso da variável RERBI, a interpretação é contrária - um impulso positivo indica valorização do real em relação à moeda das demais economias.

Ainda para todos os modelos, a variação positiva nos preços gerando resultados positivos nas exportações, pode ser justificado pelo fato deles serem apresentados como as cotações para o mercado internacional, ou seja, em dólar. Assim, um impulso por ele pode ser entendido como um aquecimento do mercado desses produtos. Para cada relação comercial o efeito dos preços terá maior ou menor influência sobre o desempenho das exportações brasileiras.

Com relação ao modelo do Brasil/China, a Figura 1 sugere que as variáveis que mais tem poder de impulsionar as 
exportações são a própria DXCH, com uma resposta predominantemente positiva; o PIBCH que gera, inicialmente, uma resposta negativa, mas depois passa a ser positiva e se estabiliza. A variação do PIB chinês é capaz de gerar um maior impulso sobre as exportações comparado à variação na cotação dos preços. O impulso negativo sobre as exportações gerado pelo PIB pode indicar que uma variação no PIB chinês seja direcionado à importação de produtos de maior valor agregado de outros parceiros, já que o país passou por um período de forte industrialização e incorporação de tecnologia no seu processo produtivo e que boa parte das exportações brasileiras direcionadas ao país são decorrentes de commodities agrícolas, ao contrário do que foi discutido anteriormente. A pequena significância na resposta gerada pela RERBICH se dá pelo fato de tanto a economia brasileira, quanto a chinesa estarem atreladas ao dólar, além da China ter um câmbio desvalorizado e fixo em relação ao dólar.

Figura 1 - Impulso Resposta do modelo Brasil/China

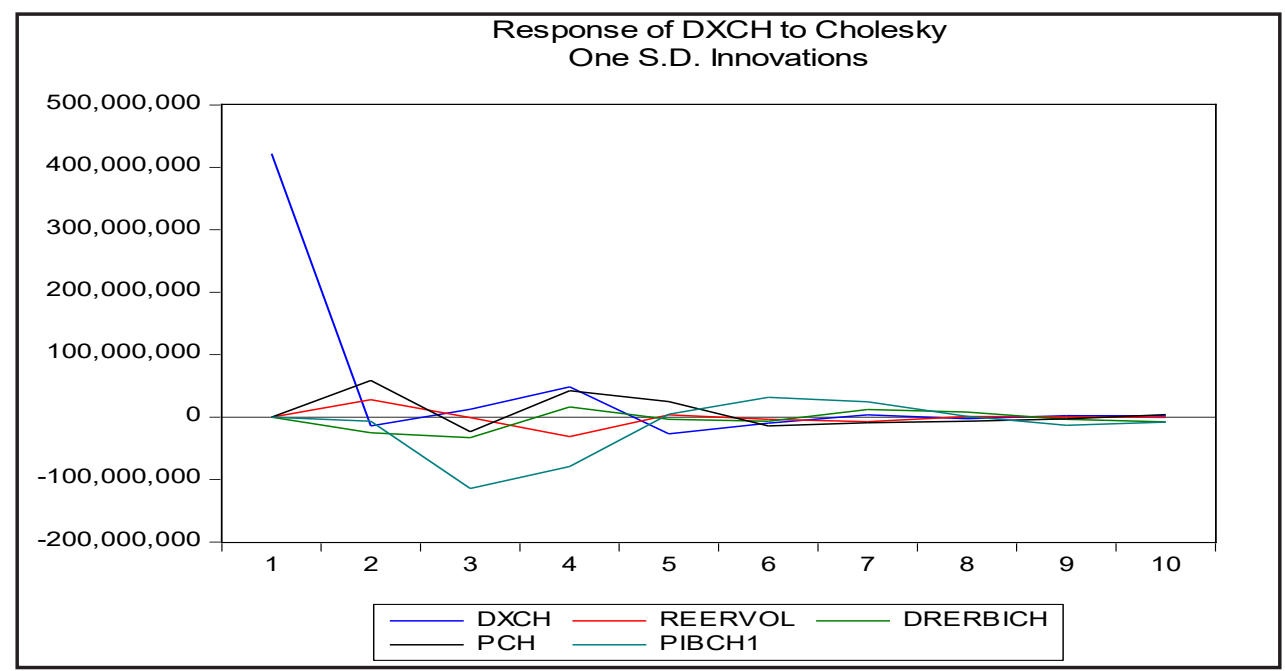

Fonte: saída do Eviews 9.0

No modelo Brasil/Estados Unidos, as respostas das exportações à impulsos das variáveis propostas são representados pela Figura 2. Nela, percebe-se que tanto o PEUA e o PIBEUA apresentam influência positiva e duradoura. Aqui, é importante ressaltar a atenção para o comportamento da resposta à REERVOL distinto em relação aos demais modelos, devido ao posicionamento de moeda referência que ocupa o dólar em qualquer relação comercial mundial e bilateral que se queira analisar.

Figura 2- Impulso Resposta do modelo Brasil/Estados Unidos

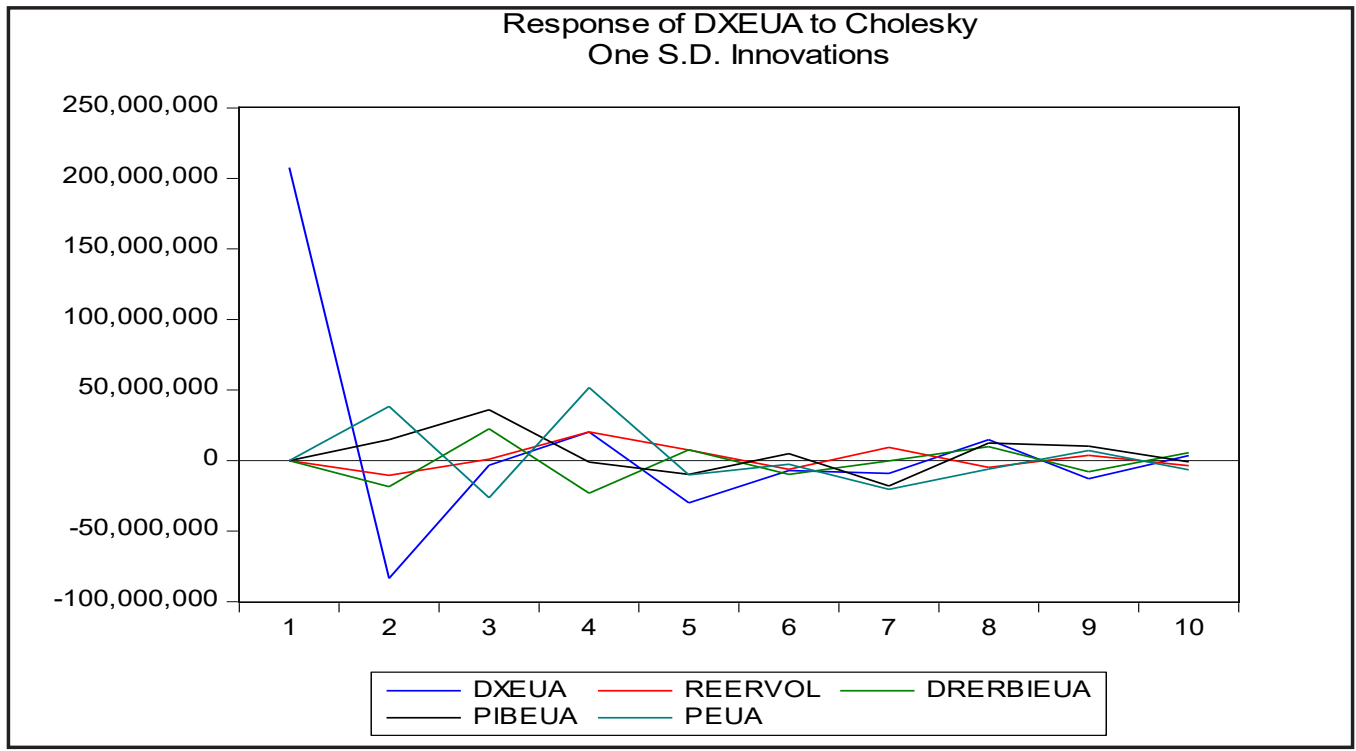

Fonte: saída do Eviews 9.0 
Ao contrário dos modelos até então apresentados, o referente ao comércio entre Brasil e Argentina, representado pela Figura 3, tem uma resposta inicialmente positiva das exportações em relação a uma variação positiva do PIB, mas ela é pouco duradoura. Isso pode ser explicado por dois fatores: a fragilidade da economia argentina devido à estagnação de seu crescimento e por boa parte dos produtos importados pelo país advindos do Brasil serem de maior valor agregado, como automóveis de passageiros e veículos de carga. A resposta em relação ao RERBIARG é pouco significativa, pois ambas as economias são fortemente dependentes do comportamento do dólar.

Figura 3 - Impulso Resposta do modelo Brasil/Argentina

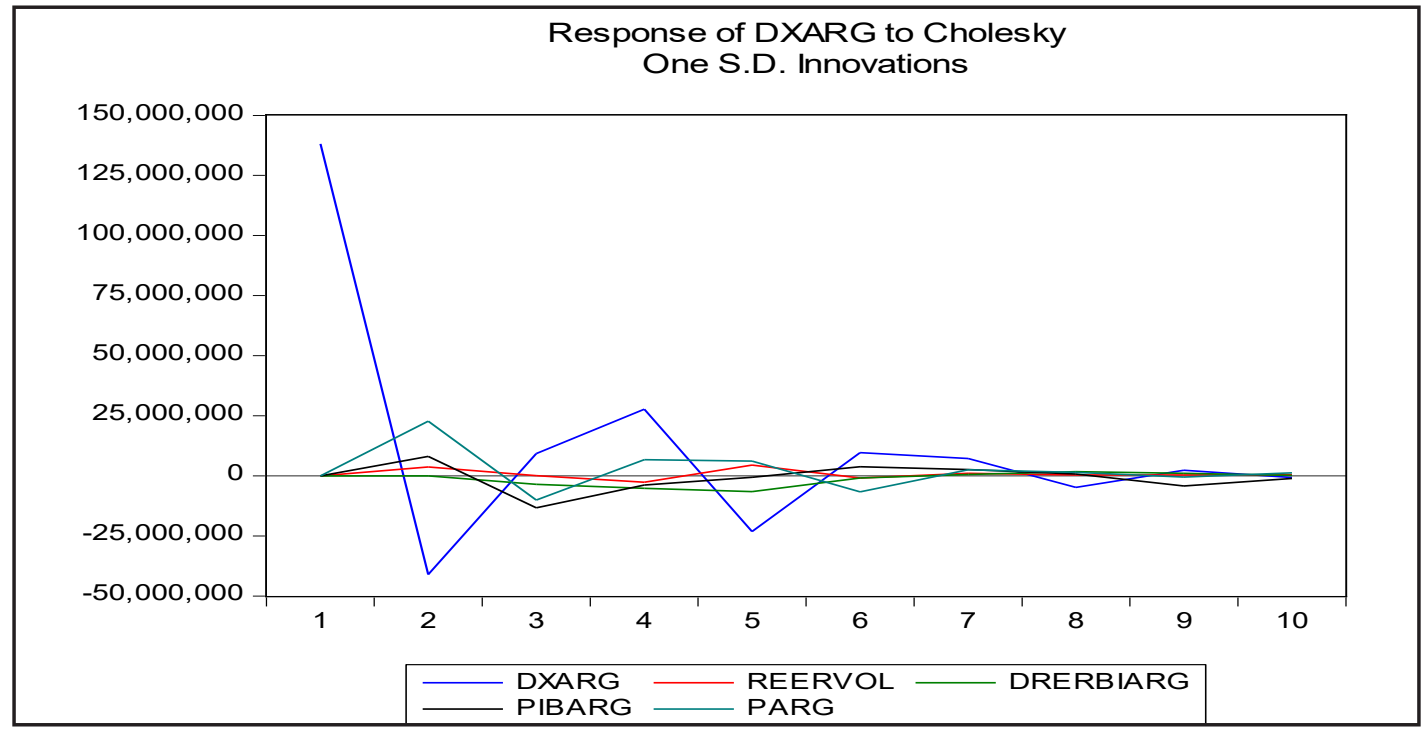

Fonte: saída do Eviews 9.0

Na Figura 4, são apresentadas as respostas do modelo Brasil/Holanda. Como comentado anteriormente, o país não tem grande representatividade como parceiro comercial do Brasil, porque apesar de apresentar a $4^{\mathrm{a}}$ colocação dos países em que as exportações brasileiras são direcionadas, no ranking das importações brasileiras, a Holanda está apenas em 16º . Isso pode justificar o porquê das respostas às variáveis escolhidas serem pouco significativas. Ainda assim, nota-se uma resposta positiva aos estímulos no PIB holandês e às desvalorizações do real em relação ao euro e, também, à variações positivas na cotação dos preços.

Figura 4 - Impulso Resposta do modelo Brasil/Holanda

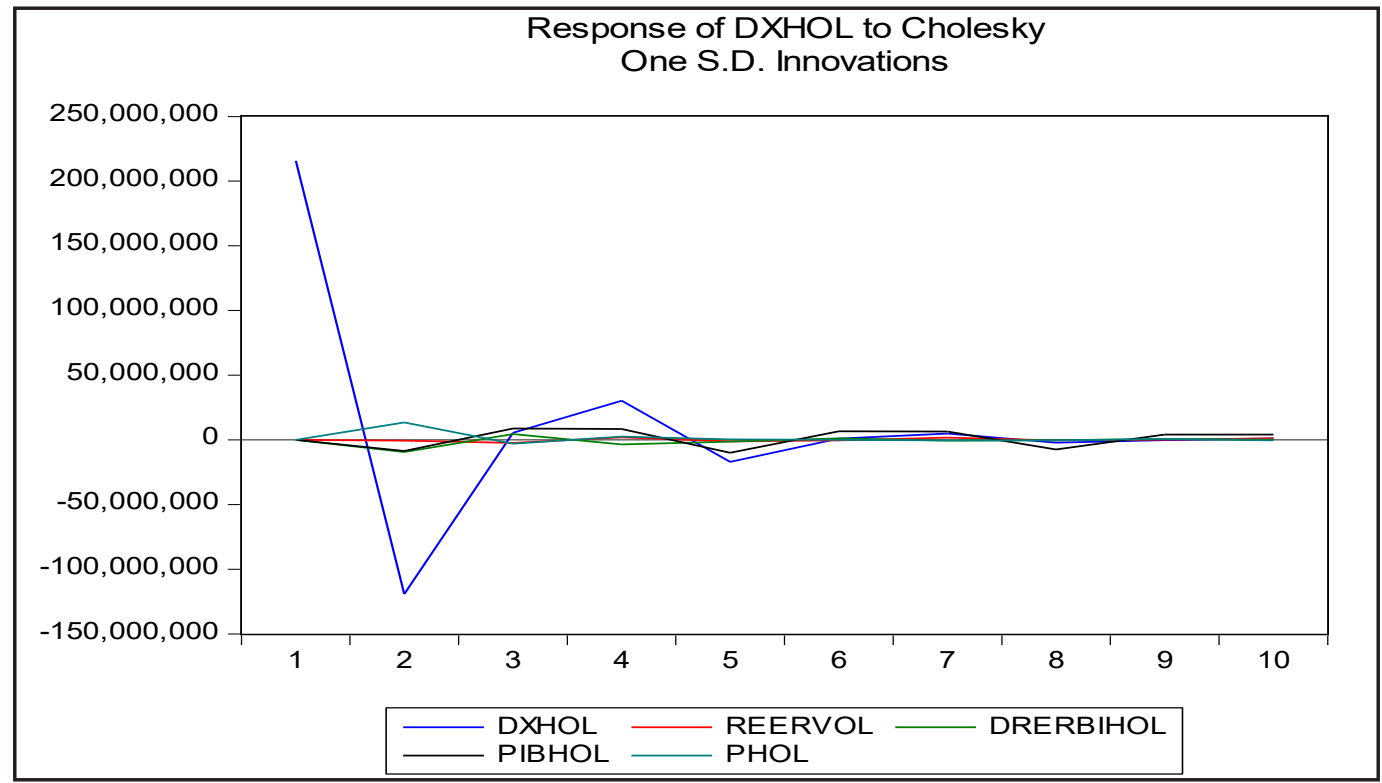

Fonte: saída do Eviews 9.0 
Por fim, o modelo Brasil/Alemanha é representado pela Figura 5 e, assim como nos modelos da China e dos Estados Unidos, os impulsos gerados pelas variáveis escolhidas geram respostas significativas às exportações. O PIBAL e o PAL geram respostas positivas e duradouras.

Figura 5 - Impulso Resposta do modelo Brasil/Alemanha

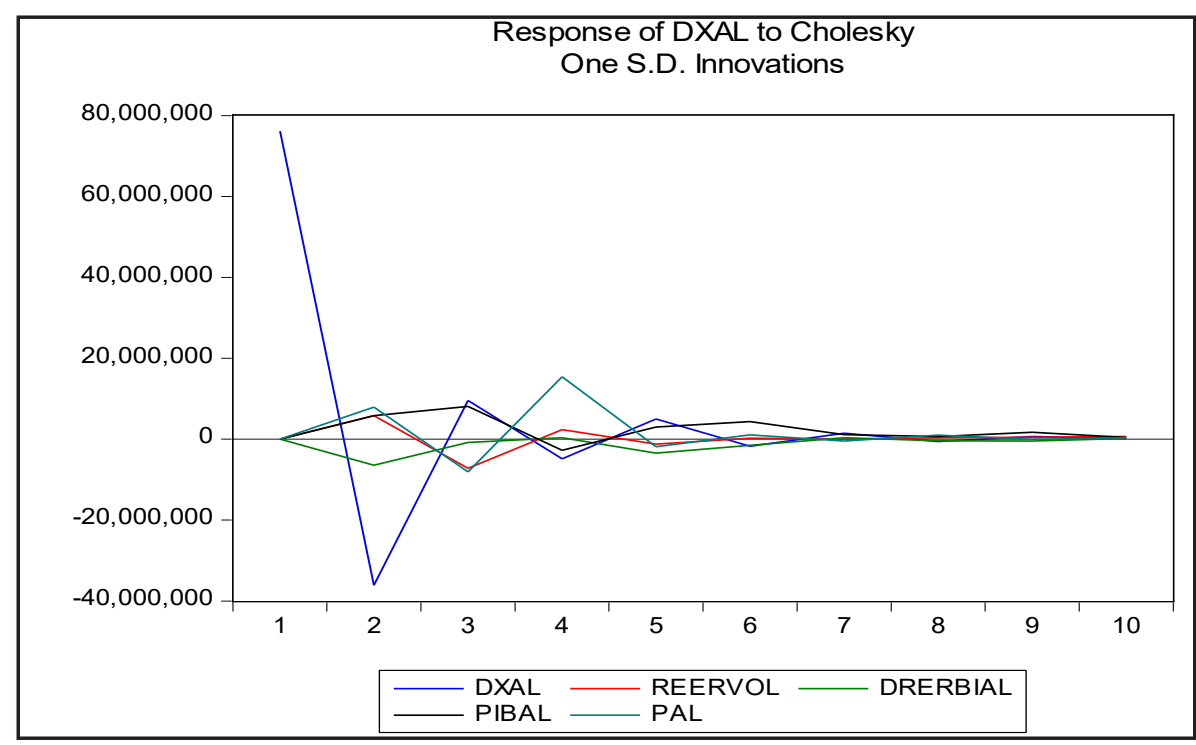

Fonte: saída do Eviews 9.0

Para o PIB, justifica-se, principalmente pela Alemanha importar, quase que na totalidade, produtos manufaturados do Brasil, ou seja, de maior valor agregado. Já para uma resposta predominantemente negativa a um impulso da RERBIAL, entende-se que uma valorização do real em relação ao euro, para o caso da Alemanha, afeta de maneira negativa as exportações brasileiras.

\section{Considerações Finais}

Desde o início do processo de globalização financeira, na década de 80, até os dias atuais, a literatura sobre o assunto é vasta. As discussões vão desde a ponderação entre as políticas adotadas pelos países diante de um processo de maior mobilidade de seus capitais, até em relação aos efeitos de variáveis como a taxa de câmbio, a taxa de juros, a paridade do poder de compra serem capazes de reagir às crises financeiras mundiais e, por consequência, gerar crescimento econômico de longo prazo. No caso do Brasil, a abertura financeira e comercial foram tardias quando comparadas às economias mais desenvolvidas e, assim como em outros países emergentes, os efeitos de um mercado aberto são distintos do que se percebe em economias desenvolvidas, como os Estados Unidos, que possuem a moeda referência na economia mundial.

Além disso, quando as economias emergentes são colocadas em análise, fatores como uma maior importância para as exportações e para as políticas de câmbio, assim como a percepção do seu nível e de sua volatilidade, além da análise dos preços do mercado de commodities são colocados em pauta. Dessa forma, em linha com os apontamentos de alguns trabalhos analisados na revisão bibliográfica, buscou-se analisar o desempenho das exportações brasileira, mas sob uma perspectiva bilateral entre o Brasil e seus principais parceiros comerciais.

A escolha das variáveis para diferentes relações comerciais mostraram que, em grande medida, os países são capazes de influenciar de maneira semelhante as exportações brasileiras, alterando apenas a intensidade com que se observa, principalmente quando as variáveis PIB de cada país e taxa de câmbio real bilateral são observadas. A variável 'preço' deve ser também destacada, pois no teste de impulso resposta, ela gera uma resposta positiva nas exportações, que diante da maneira como foi contabilizada, ou seja, a partir de cotações em dólar no mercado internacional, um aumento dos preços pode ser entendido como uma indicação de um mercado aquecido. Além disso, algumas peculiaridades merecem destaque, como o caso da China, em que uma variação do PIB pode afetar negativamente o desempenho das exportações brasileiras, mas que pode ser explicado pela sua trajetória de industrialização atrelada às características de suas importações de origem no Brasil, concentradas, principalmente, em commodities agrícolas. 


\section{Referências}

AIZENMAN, J. e BINICI, M. Exchange market pressure in OECD and emerging economies: Domestic vs. external factors and capital flows in the old and new normal. Journal of International Money and Finance, 66, p.65-87, 2016.

AIZENMAN, J. e ITO, H. East Asian Economies and Financial Globalization in the Post-Crisis World. NBER Working Paper 22268. Maio, 2016.

ARAÚJO, E. Política cambial e crescimento econômico: teorias e evidências para os países em desenvolvimento. In: Anais do I Encontro Internacional da Associação Keynesiana Brasileira, 2008.

BELluzZO, L. G. Dinheiro e as Transformações da Riqueza. In: TAVARES, M. C.; FIORI, J. L. Poder e Dinheiro: Uma Economia Política da Globalização. 5. ed. Petrópolis: Editora Vozes, 1997.

BIBOW, J. Bretton Woods 2 Is Dead, Long Live Bretton Woods 3? Levy Economics Institute of Bard College, Working Paper n⿳ำ 597, 2010.

BITTENCOURT, G. M.; CAMPOS, A. C. Determinantes das Exportações Agropecuárias Brasileiras e sua Relação com o Investimento Direto Estrangeiro. Análise Econômica, Porto Alegre, ano 32, n. 62, p. 155-176, set. 2014.

BRESSER-PEREIRA, L. C. A Doença Holandesa. In: BRESSER-PEREIRA, L. C. Globalização e Competição: Por que alguns países emergentes têm sucesso e outros não. Rio de Janeiro: Elsevier, Cap.5, p141-171, 2009

BRUEGEL. Bruegel Datasets. Disponível em: http://www.bruegel.org/datasets/

BUENO, R. de L. da. S. Econometria de Séries Temporais. CENGAGE Learning Edições Ltda, São Paulo, 2ª Edição, 2011.

DAMASCENO, A. O. Integração financeira internacional e crescimento econômico: uma crítica à abordagem convencional. Economia e Sociedade, Campinas: UNICAMP/Instituto de Economia, vol.16, nº 2 (30), p. 171 198, agosto, 2007.

EVIEWS 9.0. Quantitative Micro Software, California. Copyright (C) 2012.

EDWARDS, S. Exchange Rates in Emerging Countries: Eleven Empirical Regularities from Latin America and East Asia. NBER Working Paper, 17074, Maio, 2011.

FRANKEL, J. A. New Estimation of China's Exchange Rate Regime. Pacific Economic Review, 14:3, p. 346-360. 2009.

FROYEN, R. T. Macroeconomia. São Paulo: Saraiva, 2006.

HENRY, P. B. Capital Account Liberalization: Theory, Evidence, and Speculation. Journal of Economic Literature, Vol.45, n 4, p.887-935, 2007.

IDEC. Instituto de Estatísticas e Censo. Disponível em: www.idec.org.br.

INDEX Mundi. Disponível em: http://www.indexmundi.com.

KOSE, M. A.; PRASAD, E. S.; TERRONES, M. E. Does Openness to International Financial Flows Raise Productivity Growth? Journal of International Money and Finance, Vol.28, n4, p.554-580, 2009.

PAINCEIRA, J.P.; CARCANHOLO, M.D. Abertura Financeira e Vulnerabilidade Externa na América Latina: os impactos sobre Brasil, México e Argentina. TD.2002.004.

PAULA, L. F. Liberalização financeira, performance econômica e estabilidade macroeconômica no Brasil: uma avaliação do período recente. In: II Encontro Internacional da Associação keynesiana Brasileira, setembro,2009. 
PLIHON, D. A ascensão das finanças especulativas. Economia e Sociedade, Campinas: UNICAMP/ Instituto de Economia, vol. 5, dezembro, 1995.

RODRIK, D.; SUBRAMANIAN, A. Why Did Financial Globalization Disappoint? IMF Staff Papers, Vol. 56, nº 1, p.112-138, 2009.

VIEIRA, F. V. (2011) The new international financial crisis: causes, consequences and perspectives. Revista de Economia Política, 31:2, p.217-237, 2011.

VIEIRA, F. V. and MACDONALD, R. A Panel Data Investigation of Real Exchange Rate Misalignment and Growth. Estudos Econômicos, v. 42, p. 433-456, 2012.

VIEIRA, F. V.; Da Silva, C. G.; Holland, M. e Bottechia, L. C. Growth and exchange rate volatility: a panel data analysis. Applied Economics, v. 45, p. 3733-3741, 2013.

VIEIRA, F. V. e Gomes da Silva, C. BRICS Export Performance: An ARDL Bounds Testing Empirical Investigation. Artigo Submetido para o Encontro da ANPEC, 2016.

BANCO MUNDIAL. World Bank Indicators, 2014. Disponível em: data.worldbank.org/indicator 